\title{
The Effect of Class Size in Grades K-3 on Adult Earnings, Employment, and Disability Status: Evidence from a Multi-center Randomized Controlled Trial
}

\author{
Elizabeth Ty Wilde, $\mathrm{PhD}$ \\ Jeremy Finn, PhD \\ Gretchen Johnson, MA \\ Peter Muennig, MD, MPH
}

\begin{abstract}
Background. Early education interventions have been forwarded as a means for reducing social disparities in income and health in adulthood. We explore whether a successful early education intervention, which occurred between 1985 and 1989, improved the employment rates, earnings and health of blacks relative to whites through 2008. Methods. We used data from Project STAR (Student Teacher Achievement Ratio), a four-year multicenter randomized controlled trial of reduced class sizes in Tennessee involving 11,601 students. Students were initially randomized within 79 schools to classes with 22-25 or 13-17 students. We linked subject records to Social Security Administration (SSA) earnings and disability data collected between 1997 and 2008-when the majority of subjects were between the ages of 18 and 28 . We focused our analysis on annual, rather than cumulative, measures of earnings and employment because educational attainment after high school might reduce earnings through age 23 . We considered three or more years of statistically significant positive (or negative) annual impacts to be a meaningful effect. Results. Project STAR improved cognition and high school graduation rates. These benefits were primarily realized among low-income and minority students. These early education benefits did not translate into reduced disability claims in adulthood for treated subjects. However, exposure to small class size increased employment for blacks, and increased earnings for black males $(\mathrm{p}<0.05)$. Exposure to small classes also led to an increase in earnings for white males. However, white females exposed to small classes experienced a net decline in earnings and employment across the later years of follow up $(\mathrm{p}<0.05)$, offsetting any gains by white males. Conclusions. Exposure to small class size in grades $\mathrm{K}-3$ appears to improve earnings and employment for black males and earnings for white males, while reducing employment and earnings among white females.
\end{abstract}

ELIZABETH WILDE, GRETCHEN JOHNSON, and PETER MUENNIG are all affiliated with the Mailman School of Public Health at Columbia University. JEREMY FINN is affiliated with the State University of New York at Buffalo. Please address correspondence to Peter Muennig, MD, MPH, Mailman School of Public Health, Columbia University, 600 W. 168th Street, 6th Floor, New York, NY 10032; (347) 533-3415; pm124@columbia.edu. 
Cuccessful early education interventions, such as pre-kindergarten programs or $\checkmark$ reduced class size, hold great potential to address the social disadvantages faced by low-income and minority groups. ${ }^{1-3}$ These populations tend to have less exposure to math and complex vocabulary at home, and therefore begin school with less preparation than others. ${ }^{4}$ They are also more likely to attend under-resourced public schools. ${ }^{5}$ Early education interventions seek to remedy these social shortcomings early in life by providing cognitively enriched environments in the early years of schooling. ${ }^{6,7}$ For instance, reduced class sizes might provide disadvantaged students with more attention than they might otherwise have had in the classroom, potentially increasing cognitive skills and causing improvements in student performance. ${ }^{8}$

Improved performance in school increases the likelihood of obtaining a high school diploma - the minimum social credential needed for a living wage job. Early education interventions have been found to improve employment, improve earnings, improve health, and reduce criminal acts in adulthood., ${ }^{1,9-13}$ To date, however, the benefits of early education interventions on social outcomes in adulthood have only been studied via small randomized controlled trials, natural experiments, twin studies, or other imperfect study designs. ${ }^{11}$

Education can affect health through a large variety of mechanisms, including through increased earnings and employment. ${ }^{14}$ For instance, higher employment is linked to higher rates of health insurance coverage. Income is also strongly correlated with health and increased longevity independent of health insurance. On average, living below the poverty line predicts a greater loss in quality-adjusted life years than does being obese or smoking; all else being equal, poverty accounts for a loss of 11 million life years and 17.4 million quality-adjusted life years. ${ }^{15,16}$

Project STAR (Student Teacher Achievement Ratio) presents a unique opportunity to study the effect of one early education intervention-reduced class size in grades $\mathrm{K}-3$ - on adult health and economic outcomes through age 28 using a multi-center randomized controlled trial. ${ }^{17}$ Project STAR randomized 11,601 children within 80 schools (79 in the first year) to receive instruction in small (13-17 students), regular (22-25 students) or regular classes with a certified teacher's aide. Students who did not transfer out of a STAR school remained in the study through grade 3.

Children assigned to small classes earned higher test scores, achieved higher rates of high school graduation, and were more likely to take college entrance exams than children assigned to regular-sized classes., ${ }^{8,18,19}$ The effects were particularly noteworthy for students who spent three or four years in small classes. Assignment to small classes also appeared to produce changes in many different behavioral traits, such as task engagement. ${ }^{8,17,20}$ These benefits were realized to a greater extent among low-income and minority students than among non-poor and White students, suggesting that small classes disproportionately helped socially disadvantaged students. ${ }^{2,8}$

Children assigned to small classes were also found to have higher mortality through age 29. ${ }^{21}$ In a study that linked Project STAR to National Death Index records, improved cognition was inversely correlated with mortality. While it was not clear why exposure to small class size increased mortality, the higher mortality could have come through the effect of small class size on increased peer interactions. Increased peer interactions in childhood through early adulthood can lead to increased experimentation with 
drugs, firearms, and automobile use-the major causes of excess death among those exposed to small class size.

In the present study, we linked Project STAR participants with their Social Security Administration (SSA) records, to measure each subject's employment, earnings, and disability claims between 1997 and 2008. Our objective was to explore the extent to which small class sizes in childhood might affect health and economic disparities in adulthood. Specifically, for the 1997-2008 period, representing the approximate date of Project STAR subjects' graduation from high school through the most recently available data, we obtained mean earnings, annual earnings, years employment, annual employment and disability status.

\section{Methods}

Randomization. The Project STAR schools were located in inner-city, urban, suburban, and rural areas. In the fall of the 1985-1986 school year, both teachers and students in kindergarten were randomized to small, regular, or regular with aide classes using random number tables (Figure 1). New teachers were assigned to the classes at random in each subsequent year. All students were required to remain in their assigned class,

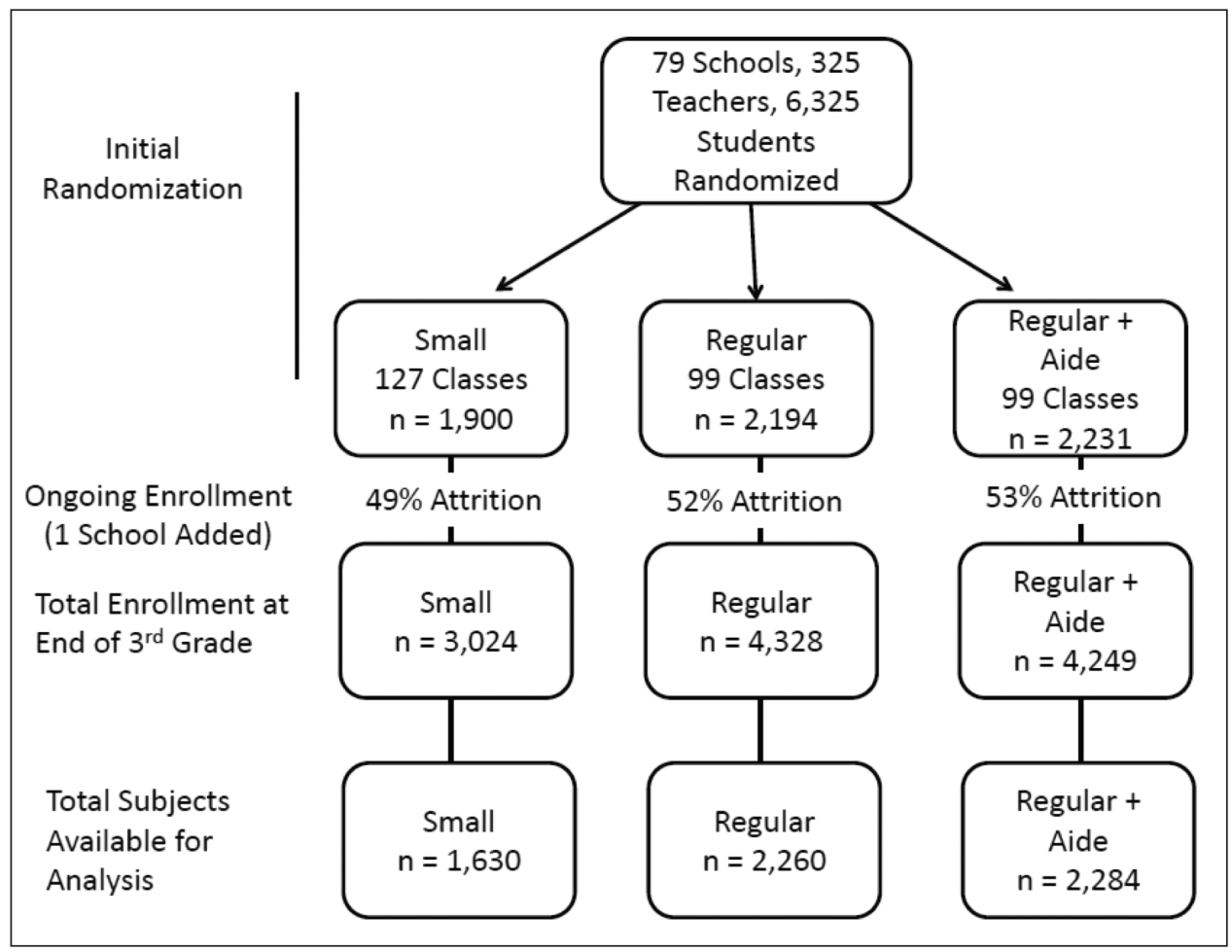

Figure 1. The initial randomization, ongoing enrollment, attrition, and successful electronic data records linkage of subjects in the Project STAR (Student Teacher Achievement Ratio) experiment with Social Security Administration data. 
and the Project STAR research staff regularly conducted audits to ensure adherence to assignment. All students returned to regular size classes after third grade, when the experiment ended. Randomization was successful, with just one student, to our knowledge, switching from a regular class to a small class in the period following the initial assignment. ${ }^{22}$

Over the course of the experiment, however, some students left Project STAR schools, and others joined. The research staff randomly assigned newly matriculating students to all three class types. Over the final three years of the study, $22.5 \%$ of the students changed assignment, almost two thirds of whom (65.9\%) moved between regular and regular plus aide classes. To alleviate parental concerns regarding the absence of an aide for children assigned to larger classes, researchers had re-randomized students between the two regular size class types after kindergarten. ${ }^{22}$

While this variation in treatment allows us to estimate dose-response effects, it also requires that we employ an intent-to-treat analysis. In the intent-to-treat analysis, some partially treated children are counted among the untreated students, and some partially untreated children are counted among the treated students. The resulting effect sizes in this approach are smaller than they would be had all children remained in their original assignments.

Data linkage. We linked records from Project STAR to SSA data using unique identifiers collected from STAR participants. The SSA uses identifiers (Social Security number, name, date of birth, and gender) and probabilistic matching techniques to match administrative data to SSA data; records can be matched even if some fields are missing or inaccurate (see technical appendix). Match priorities are determined by the relative importance of the identifier, with the Social Security number taking the highest priority, and the name the second highest. For instance, a record with a perfect match on the Social Security Number and name is still considered a match even if the gender and date of birth are incorrect. Out of 11,601 original participants, 6,257 (54\%) had SSA records considered to be a validated match.

Statistical analyses. We wrote programs using SAS 9.2 (SAS Institute Inc., Cary, NC) prior to submitting them to the SSA for use with the appropriately verified records. The study design does not permit simple comparisons among the three class types because randomization occurred within schools, and because there was year-to-year student mobility into and out of the three groups. We therefore applied previously validated methods for estimating effects within the Project STAR cohort. ${ }^{18,22}$ Specifically, the adjusted analyses assumed the basic form (using SAS procedure GENMOD):

$$
\mathrm{Y}_{\mathrm{ics}}=\beta 0+\beta 1 \text { SMALL }_{\mathrm{cs}}+\beta 2 \text { REGAIDE }_{\mathrm{cs}}+\mathbf{X}_{\mathrm{ics}} \gamma+\alpha_{\mathrm{sw}}+\mathrm{v}_{\mathrm{ics}}
$$

where SMALL is a binary variable indicating initial enrollment in small classes. REGAIDE is a binary variable indicating initial enrollment in a regular class with an aide. $\mathrm{Y}_{\mathrm{ics}}$ represents an outcome for individual i in class $\mathrm{c}$ in school $\mathrm{s}$. $\alpha_{\mathrm{sw}}$ represent school, entrywave and school-by-entry wave fixed effects, so that identification is based on within school comparisons between students entering Project STAR at the same time. $\mathbf{X}_{\mathrm{ics}}$ represents a vector of student-level covariates. Finally, the error term 
$\mathrm{v}_{\text {ics }}$ contains individual-level, class-level and school-level components. We clustered on initial classroom identifiers to account for these common class-level components.

Following Schochet et al. and the recommendations of the SSA, we restrict all analyses to those participants with validated SSA records, and counted validated matches without earnings records as having zero earnings. ${ }^{23}$ Due to confidentiality restrictions, we did not access the data directly, but instead submitted program files to the SSA, where analysts ran the programs and then provided outputs for cell sizes greater than 10 .

To construct annual earnings, we added total uncapped Medicare earnings to selfemployment earnings. A person with positive earnings in a given year was considered employed. Negative earnings were recoded as 0 . Disability was ascertained based upon whether in the most recent application for Social Security Disability Insurance benefits an individual was approved for payment. The technical appendix, all programs, and output are available at http://www.pceo.org/STAR.html.

Our outcomes are not corrected for multiple comparisons, as a Bonferonni correction would be too conservative a criterion for correcting results over many years of follow-up and across many sub-groups. Rather, for our annual earnings and employment analyses, we present results that are significant only for those instances when at least three annual earnings or employment values are statistically significant for a given sub-group.

This study was approved by the Columbia University Institutional Review Board. Because data linkage was performed on electronic records only, and only within a secure environment at the Social Security Administration, informed consent was not possible or required.

\section{Results}

In the first year of the study, 6,325 children were randomized to kindergarten classrooms in 79 schools. There were no significant differences in any of the measured sociodemographic characteristics between subjects in any of the experimental groups after randomization (Table 1). Subsequent differences in socio-demographic characteristics across class types in later years occurred due to student mobility (see technical appendix), but this did not affect our intent-to-treat analysis. Rather, it allowed us to estimate dose-response effects.

In the regression analysis, none of the means for years of employment, mean earnings, or disability were significantly different from each other across the three experimental groups (see Table 2). In the subgroup analyses of disability, mean earnings, and years of employment, however, there were marginally significant decreases in years of employment for Whites, and significant decreases in mean earnings and employment for White women $(\mathrm{p}<.05)$.

However, it is inappropriate to only measure the impact of small class size on cumulative earnings at age 28 because exposure to small class size may also increase college enrollment, and college students tend to have much lower earnings than full-time workers. In Figure 2, we present annual earnings for those groups who had at least three years of higher or lower earnings or employment $(\mathrm{p}<.05)$ over the 1997-2008 follow-up period. 


\section{Table 1.}

\section{DEMOGRAPHIC CHARACTERISTICS OF PROJECT STAR PARTICIPANTS BY GROUP ASSIGNMENT FOR STUDENTS ENROLLED IN KINDERGARTEN AND FOR ALL YEARS OF ENTRY COMBINED}

\begin{tabular}{lccc}
\hline \hline Variable & $\begin{array}{c}\text { Small } \\
\text { Classes }\end{array}$ & $\begin{array}{c}\text { Regular } \\
\text { Classes }\end{array}$ & $\begin{array}{c}\text { Regular } \\
\text { Classes } \\
\text { with Aide }\end{array}$ \\
\hline Students randomized in kindergarten & & & \\
$\quad$ Number of subjects & 1,900 & 2,194 & 2,231 \\
Actual class size & 15.1 & 22.4 & 22.8 \\
Mean age at enrollment & 5.4 & 5.4 & 5.4 \\
Gender (\% female) & 48.6 & 49 & 48.3 \\
Race (\% White/Asian) & 68.3 & 67.5 & 65.9 \\
Ever Eligible for Free Lunch & & & \\
All students, regardless of entry year & 47.1 & 47.7 & 50.3 \\
Number of subjects & & & 2,284 \\
Total Disabled (N) Ever & 1,630 & 2,260 & 40 \\
Mean Earnings & 25 & 38 & $12,456.6$ \\
Years Employed & $12,647.8$ & $12,617.4$ & 9.91 \\
\hline
\end{tabular}

aStudents who qualify for free lunches are in families earning less than $130 \%$ of the federal poverty level.

Blacks who were randomized to small class size in childhood had higher employment in 2000, 2005, and 2006 ( $\mathrm{p}<.05$, each year). Black males in the experimental group had higher earnings in 1999-2001, and in 2008 ( $\mathrm{p}<.05$, each year). White males in the experimental group had higher earnings in 2003-2005 and White females in the experimental group had lower earnings in 2005-2007 ( $<<.05$, each year). Finally, subjects who had received three years of treatment had significantly lower earnings in the 1998-2004 period ( $\mathrm{p}<.05$, each year, data not shown). While this became nonsignificant post-2004, the downward trend more or less continued through 2008.

In the remaining sub-group analyses, we found no significant differences in earnings or employment when we apply our criterion of at least three years of significant results. However, some significant differences were nonetheless noted in specific years. Specifically, females overall and subjects who had ever qualified for free lunch had negative earnings in 2008. Whites overall had lower employment in 2001 and 2003. Those who attended grades K-3 in an urban setting had positive earnings in 2003 and 2004 but negative employment in 2001. Finally, those in an inner city environment had positive employment in 1999 and 2000. With the exception of a tendency for most groups to realize a downward turn in earnings around 2007-8, and a trend toward 


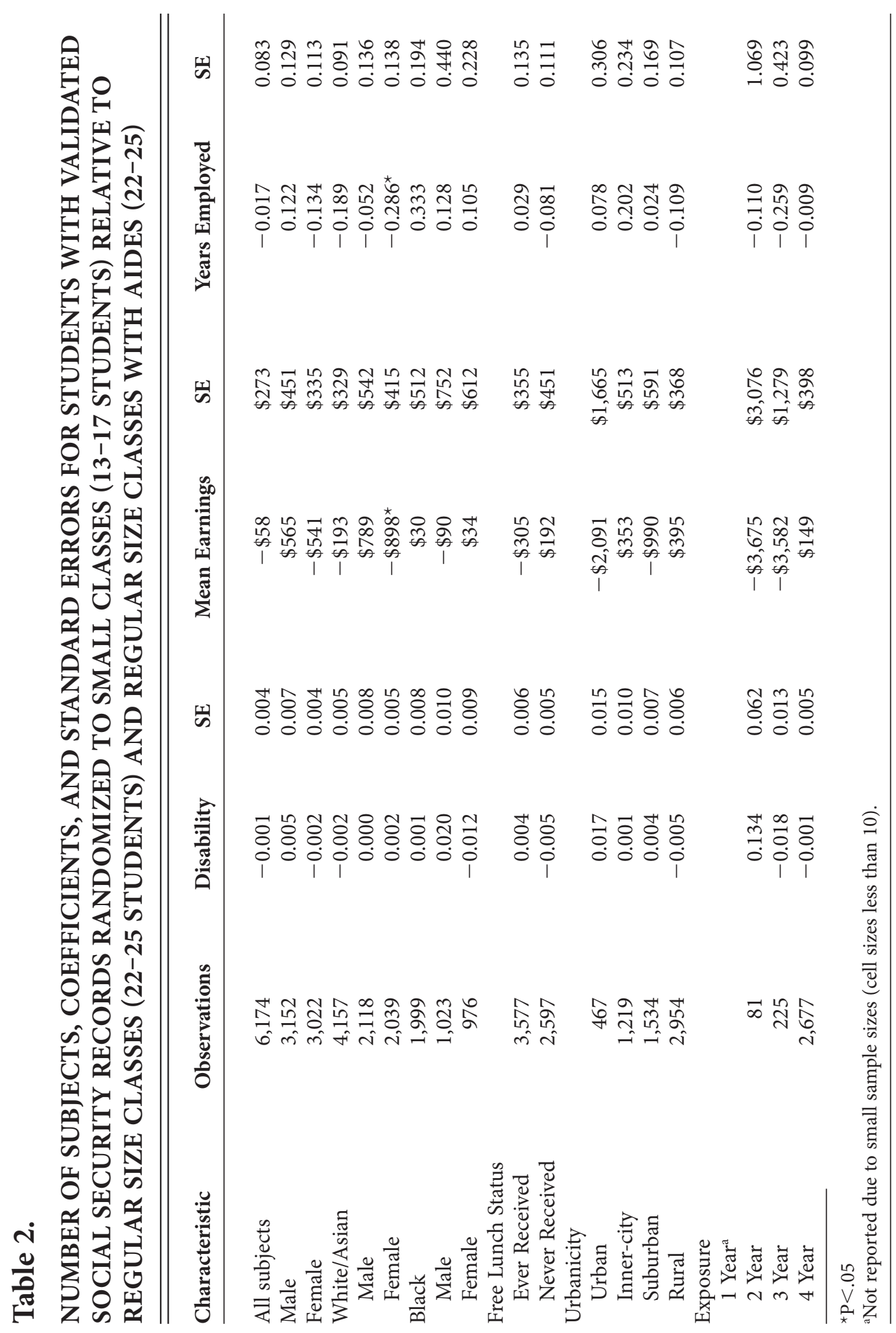



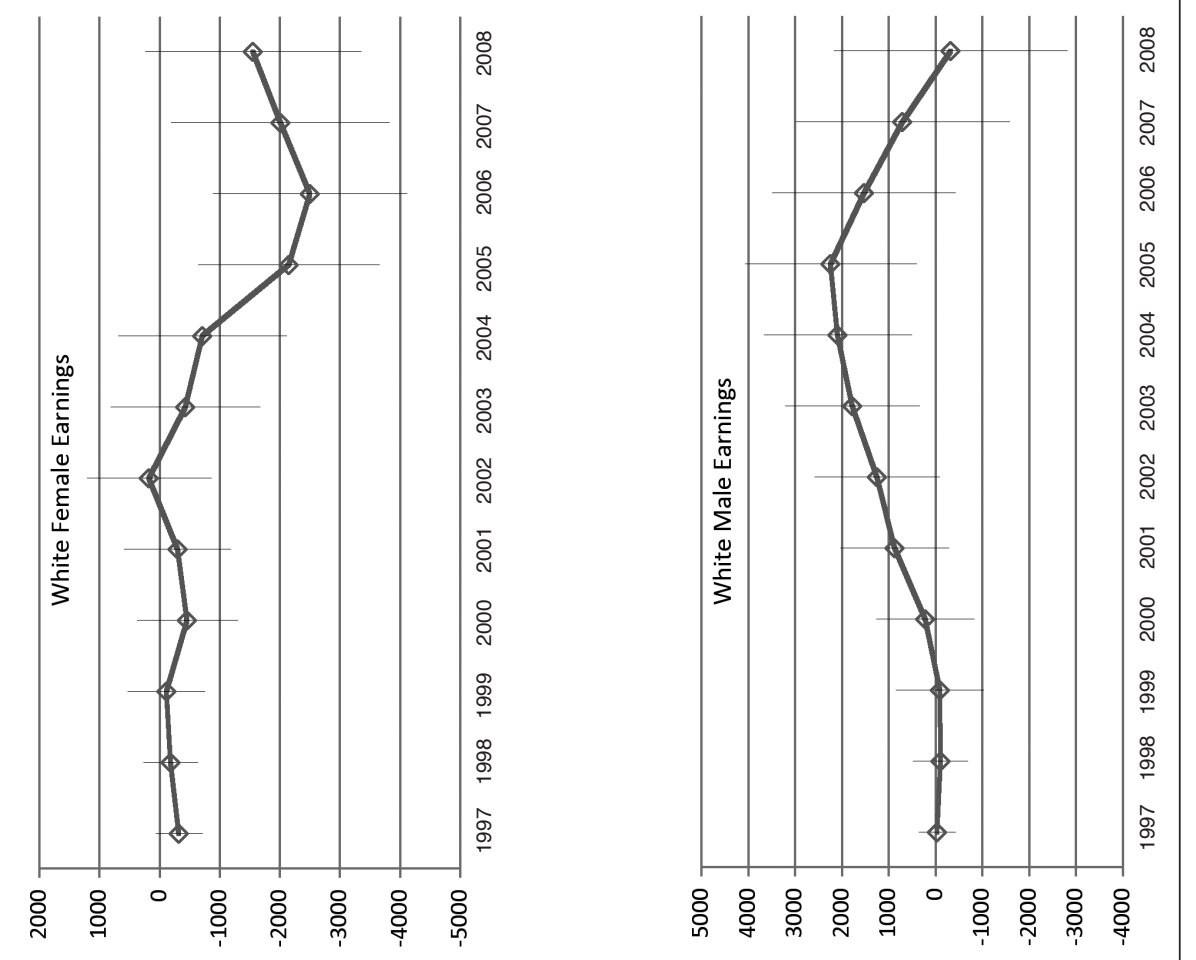

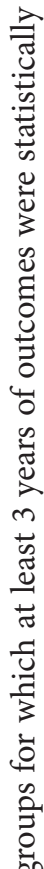

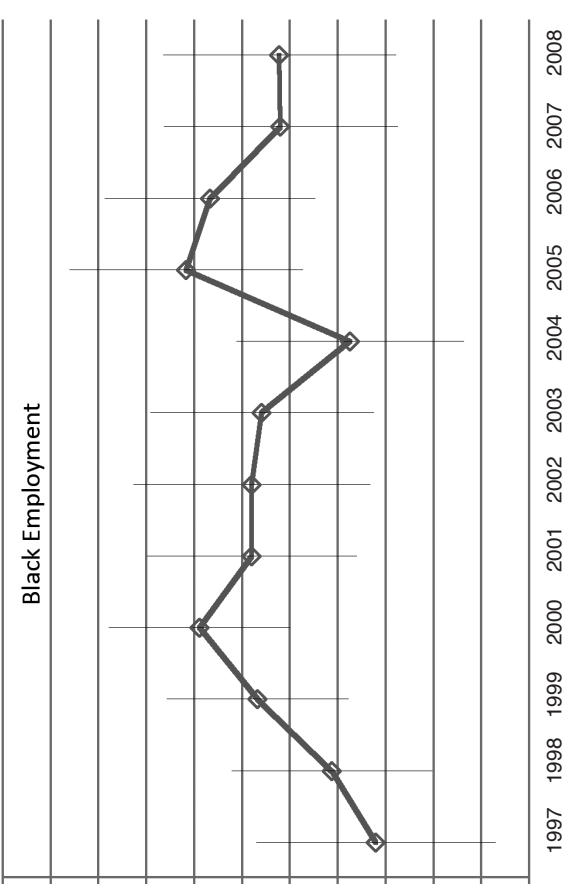

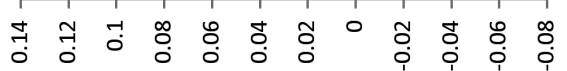

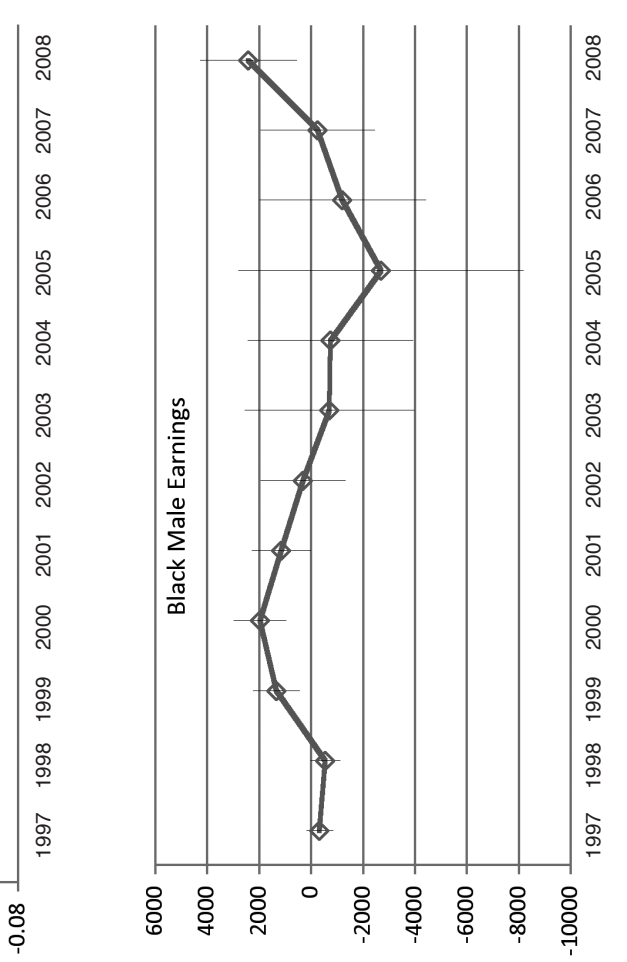

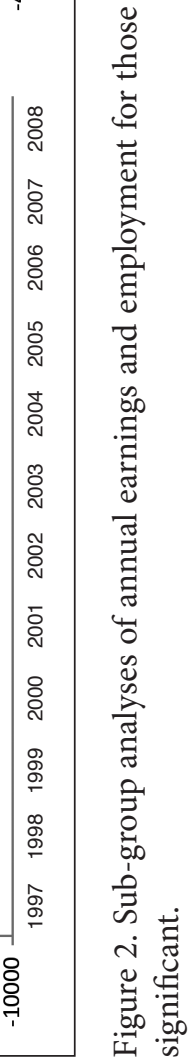


higher earnings among males in the post-college years, none of these relationships demonstrated clear temporal trends.

There were no differences between treated and untreated subjects with respect to disability for any sub-group or in any year.

Robustness checks. Our results were not affected by any of our robustness checks, which included treating those missing earnings records as missing values rather than 0 earnings, including those missing covariates (e.g., gender, free lunch), clustering on school assignment, and using robust standard errors rather than clustered standard errors.

\section{Discussion}

We present the first findings from a multi-center randomized controlled trial on the adult effects of a successful childhood education intervention. Conventional wisdom suggests that we would expect to find significant increases in employment and earnings among treated subjects after around age 25, by which time most Americans have finished their education. ${ }^{12}$ Prior to this, we would expect to see lower earnings and employment among treated subjects than control subjects because we believe that they may be more likely to attend college than to enter the workforce immediately after high school.

While overall annual trends in employment and mean earnings did not differ between treated and untreated subjects, we found interesting sub-group trends. First, Blacks, and particularly Black males, benefited from exposure to small class size with respect to annual employment and earnings. This is largely consistent with earlier studies, which found that Project STAR disproportionately impacted the percentage of Black students who graduated from high school and who took college-entrance exams (SAT and ACT). ${ }^{2}$ It is also consistent with adult earnings data from other early intervention programs targeted toward Black children. ${ }^{10,24}$ The year-to-year pattern was also fairly consistent with the expectation that employment and earnings would rise over time. However, a dip was seen in the 2003-2006 period for unclear reasons.

Second, we found that White males benefited with respect to earnings after 2003. However, lower employment and earnings among White females offset these gains. While we were unable to test the relationship between these findings and marriage rates, this observation is consistent with the positive correlation between a high school diploma and marriage into male-headed households. ${ }^{25}$ Marriage is somewhat less common among blacks than among whites, but we also observed significant changes in earnings among black males alone.

Year-to-year patterns did show a gradual rise among White male earnings after about year 4 of follow-up, but an unexpected decline was noted starting around year 9 . This decline as followed by a parallel increase in female earnings. We also noted that those students who received three years of exposure to Project STAR showed a general decline over time in earnings. While the statistically-significant portion of this decline during college attendance is consistent with expectations, we cannot explain why the downward trend continued, even if non-significant.

Our overall findings on employment and earnings were largely in line with a study 
that was conducted in parallel using data from the Internal Revenue Service. ${ }^{26}$ This study focused on teacher and peer effects rather than small class size effects, and therefore did not explore distributional effects of exposure to small class size on adult outcomes in detail. Those researchers, like us, found a small and non-significant increase in overall earnings associated among those participants assigned to small class size.

Conventional wisdom also holds that enhanced education should reduce disability among treated subjects. ${ }^{14}$ However, in a previous analysis, we found a higher mortality rate among treated subjects using a different data linkage (the National Death Index), and speculated that this was due to the impact of small class size on sociability. ${ }^{21}$ Because not all accidents are fatal, and accidents are a primary cause of disability, we anticipated that the disability data would mirror the mortality data. But we found no indication of any effect of small class size on disability.

Our power calculations for disability were based on an earlier study of the effect of Project STAR upon mortality. ${ }^{21}$ The study was adequately powered to detect a difference of less than 1 standard deviation at a power of 0.8 , or roughly a two-fold overall risk of disability between the groups. Thus, this analysis was only adequately powered to detect relatively large differences in disability between the experimental and control groups for the overall sample.

The primary challenge of our study was statistical power, particularly for the subgroup analyses. While Project STAR was a large study, our analysis was restricted to only individuals with validated Social Security records. Of the original 11,601 subjects, only 6,257 had validated Social Security records. While treatment status does not predict validation code, other characteristics, including entry wave and school assignment were significantly predictive, suggesting that our results may not be representative of the entire STAR sample. This may be due to a crosscheck of identification data in the years following randomization.

Many subjects were almost certainly working in the informal sector. One other randomized trial, Job Corps, was able to collect both self-reported earnings and employment data and administrative data. ${ }^{23}$ That study examined the impact of a job-training program on earnings (among other outcomes). As in Project STAR, treated subjects were also more likely to obtain additional schooling. That study found that the administrative records probably underestimated the overall program impact on earnings. ${ }^{23}$ However, they had no way of precisely estimating the extent to which self-report data over-estimated earnings or administrative data underestimated earnings. We therefore must consider our analysis as bearing on formal sector earnings only; furthermore, even among formal sector earnings, some types of earnings may be excluded from Social Security (e.g., some workers in the agriculture sector). ${ }^{27}$ In addition, our method of assessing disability may miss some people who were granted disability at one time, but then denied in a subsequent application for disability benefits.

Despite these limitations, we find that Project STAR produced a positive impact on Black employment and, in particular, on the earnings of Black males. Reduced class size interventions are designed specifically to address early life disadvantage, and our findings are consistent with past research showing that early education interventions are successful at doing so for Black males. Small class size may be an effective way of 
reducing economic disparities between Blacks and Whites, and Black males in particular. However, further follow-up will be needed to ascertain whether early education interventions will have long-term effects on mortality, disability, and earnings.

\section{Notes}

1. Currie J. Early childhood education programs. J Econ Perspectives. 2001;15(2):213-38.

2. Krueger AB, Whitmore DM. Would smaller classes help close the Black-White achievement gap? Princeton, NJ: Princeton University, 2009.

3. Dobbie W, Fryer RG. Are high quality schools enough to close the achievement gap? Evidence from a social experiment in Harlem. Washington, DC: National Bureau of Economic Research, 2009.

4. Hart B, Risley TR. Meaningful differences in the everyday experience of young American children. Baltimore, MD: Paul H. Brookes Pub. Co., 1995.

5. Alonso G, Anderso N, Su C, et al. Our schools suck: students talk back to a segregated nation on the failures of urban education. New York, NY: New York University Press, 2009.

6. Lazar I, Darlington R, Murray H, et al. Lasting effects of early education: a report from the Consortium for Longitudinal Studies. Monographs of the Society for Research in Child Development. 1982;47(2-3):1-151.

7. Levin H, Belfield C. The price we pay: economic and social consequences of inadequate education. Washington, DC: Brookings Institution Press, 2007.

8. Finn JD, Gerber SB, Achilles CM. The enduring effects of small classes. Teachers College Record. 2001 Apr;103(2).

9. Schweinhart LJ, Montie J, Xiang Z, et al. The High/Scope Perry preschool study through age 40. Ypsilanti, MI: High/Scope Press, 2005.

10. Campbell FA, Ramey CT, Pungello E, et al. Early childhood education: young adult outcomes from the Abecedarian Project. Applied Developmental Science. 2002; 6(1):42-57.

11. Muennig P, Schweinhart L, Montie J, et al. Effects of a prekindergarten educational intervention on adult health: 37-year follow-up results of a randomized controlled trial. Am J Public Health. 2009 Aug;99(8):1431-7.

12. Carneiro P, Heckman JJ. Human capital policy. In: Heckman J, Krueger A, eds. Inequality in America: what role for human capital policies? Cambridge, MA: MIT Press, 2003.

13. Muennig P, Robertson D, Johnson G, et al. The effect of an early education program on adult health: the Carolina Abecedarian Project randomized controlled trial. Am J Public Health. 2011 Mar;101(3):512-6.

14. Kawachi I, Adler NE, Dow WH. Money, schooling, and health: mechanisms and causal evidence. Ann N Y Acad Sci. 2010 Feb;1186:56-68.

15. Muennig P, Fiscella K, Tancredi D, et al. The relative health burden of selected social and behavioral risk factors in the United States: implications for policy. Am J Public Health. 2010 Sep;100(9):1758-64.

16. Muennig P, Franks P, Jia H, et al. The income-associated burden of disease in the United States. Soc Sci Med. 2005 Nov;61(9):2018-26.

17. Finn JD, Achilles CM. Tennessee's class size study: findings, implications, misconceptions. Educational Evaluation and Policy Analysis. 1999;21(2):97.

18. Krueger AB, Whitmore DM. The effect of attending a small class in the early grades 
on college-test taking and middle school test results: evidence from Project STAR. Economic Journal. 2001;111(468).

19. Finn JD, Gerber SB, Boyd-Zaharias J. Small classes in the early grades, academic achievement, and graduating from high school. J Educ Psychol. 2005;97(2):214-23.

20. Finn JD, Pannozzo GM. Classroom organization and student behavior in kindergarten. Journal of Educational Research. 2004;98(2):79-92.

21. Muennig P, Johnson G, Wilde ET. The effect of small class sizes on mortality through age 29 years: evidence from a multicenter randomized controlled trial. Am J Epidemiol. 2011 Jun 15;173(12):1468-74. Epub 2011 May 3.

22. Krueger AB. Experimental estimates of education production functions. Quart J Econ. 1999 Jun;114(2):497-531.

23. Schochet P, Burghardt J, McConnell S. National job corps findings: studies using administrative data (final report, 2003). Princeton, NJ: Mathematica Policy Research Inc., 2008.

24. Belfield CR, Nores M, Barnett WS, et al. The High/Scope Perry preschool program. Journal of Human Resources. 2006;41(1):162-90.

25. U.S. Bureau of the Census. Census 2000. Washington, DC: U.S. Bureau of the Census, 2009.

26. Chetty R, Friedman J, Hilger N, et al. How does your kindergarten classroom affect your earnings? Evidence from project STAR. Quarterly J Econ. 2011 (in press).

27. Katznelson I. When welfare was White: the untold history of racial inequality in twentieth century America. New York, NY: Norton, 2005. 